\title{
The Physiological Characters and Flagellar Arrangement of Motile Homofermentative Lactobacilli
}

\author{
By MARGARET GEMMELL \\ Department of Bacteriology, School of Agriculture, Edinburgh \\ AND W. HODGKISS \\ Torry Research Station, Aberdeen
}

(Received 28 February 1964)

\section{SUMMARY}

The biochemical and physiological characters of 28 strains of motile lactobacilli isolated from silage, and of two motile strains of Lactobacillus salivarius, are described. The silage organisms belong to the homofermentative low-temperature group but their properties are different from those of $L$. casei and $L$. plantarum. Flagella-stained preparations and electron micrographs of two strains show that they have numerous peritrichous flagella.

\section{INTRODUCTION}

When examining lactobacilli in silage 28 motile strains were isolated. Among the isolates from silage made from several crops of ryegrass and cocksfoot, at various stages of maturity, the motile strains represented $29 \%$ of the homofermentative low-temperature group. There are several reports in the literature of motile strains in this subdivision of Lactobacillus, but in some cases the descriptions given suggest that the organisms may have been similar to Lactobacillus salivarius. In the study about to be described the properties of the recent isolates and of two strains of $\boldsymbol{L}$. salivarius were examined. There is little published information about the type of flagellar arrangement in the lactobacilli and this aspect received particular attention.

\section{METHODS}

Organisms. These were 28 strains of lactobacilli isolated from silage on the selective medium of Keddie (1951) and two strains of Lactobacillus salivarius, Ho 66 received from Dr M. Rogosa and ATcC 929 from Dr M. Elisabeth Sharpe.

Media. The basal medium which was used throughout with minor modifications had the following constituents in 11 . tap water: meat extract (Lab Lemco), 5 g.; Evans peptone, 5 g.; Difco yeast extract, 5 g.; Tween $80,0.5 \mathrm{ml}$.; $\mathrm{MnSO}_{4} .4 \mathrm{H}_{2} \mathrm{O}$, $0 \cdot 1 \mathrm{~g}$.; potassium citrate, $1 \mathrm{~g}$.; $\mathrm{pH} 6 \cdot 5$.

Fermentation reactions. Yeast autolysate $(5 \cdot 0 \%, \mathrm{v} / \mathrm{v})$ prepared as in Gibson, Stirling, Keddie \& Rosenberger (1958) was substituted for yeast extract in the basal medium. Davis agar $(0 \cdot 15 \%, \mathrm{w} / \mathrm{v})$ and bromocresol purple $(2 \cdot 8 \mathrm{ml}$. of a $1 \cdot 6 \%, \mathrm{w} / \mathrm{v}$, ethanolic solution/1.) or bromocresol green $(5 \cdot 6 \mathrm{ml}$. of a $0.4 \%, \mathrm{w} / \mathrm{v}$, aqueous solution/l.) were added. Media containing bromocresol purple were adjusted to $\mathrm{pH} \mathbf{7 \cdot 0}$; those containing bromocresol green to $\mathrm{pH} 5 \cdot 4$. Fermentable substrates $(0 \cdot 5 \%, \mathrm{w} / \mathrm{v}$, 
final concentration) were Seitz-filtered and added at $45-50^{\circ}$ to the autoclaved medium. A Pasteur pipette was used to inoculate 8-10 ml. of the melted medium (Whittenbury, 1963).

Production of slime from sucrose. Cultures were streaked on plates of basal medium ( $\mathrm{pH} 7)$ containing agar $(1.5 \%, \mathrm{w} / \mathrm{v})$ and sucrose $(5.0 \%, \mathrm{w} / \mathrm{v})$. These were incubated for 7 days at $22^{\circ}$. The slimy growth from the plates was harvested and dispersed in a small amount of distilled water. The bacteria were centrifuged down and the supernatant fluid treated with ethanol to give a precipitate which was centrifuged down and redissolved in $\mathrm{N}_{-}-\mathrm{H}_{2} \mathrm{SO}_{4}$. This solution was then heated at $100^{\circ}$ for $10 \mathrm{~min}$. to hydrolyse the slime, neutralized with barium hydroxide, and the precipitate removed by centrifugation. The supernatant fluid was examined for sugars by paper chromatography, with glucose and fructose as markers. The solvent used was a mixture of propionic acid + butanol + water $(1+2+2$, by vol. $)$. After running for $24 \mathrm{hr}$ the chromatogram was dried and sprayed with a saturated solution of aniline oxalate and the paper heated at $90-100^{\circ}$ for $1 \mathrm{hr}$. The slime was assumed to be dextran since the only spot produced on the chromatogram had an $R_{F}$ value corresponding to that of glucose.

Malate and citrate dissimilation. The media used were: (1) Basal medium $+1 \%$ (w/v) glucose $+4 \%$ (w/v) malic acid, neutralized with KOH. (2) As (1) but without glucose. (3) Basal medium $+3 \%(w / v)$ potassium citrate $+1 \%(w / v)$ glucose. (4) As (3) but without glucose. These media were distributed in $5 \mathrm{ml}$. amounts in $6 \times \frac{1}{2}$ in. test-tubes containing fermentation tubes. After inoculation the tubes were sealed with water agar.

Production of catalase. (1) Slopes of basal medium to which had been added glucose $(0.05 \%, \mathrm{w} / \mathrm{v})$ and agar $(1.5 \%, \mathrm{w} / \mathrm{v})$ were inoculated and incubated for 2 days. Peroxide-splitting activity was judged visually by effervescence on the addition of hydrogen peroxide (10 vol.) to heaped growth. (2) Agar $(1.5 \%, \mathrm{w} / \mathrm{v})$ and glucose $(0.5 \%, \mathrm{w} / \mathrm{v})$ were added to the basal medium. To $90 \mathrm{ml}$. of this medium (melted) were added $10 \mathrm{ml}$. of a $1+1$ (by vol.) mixture of defibrinated ox-blood and tap water. The medium was heated at $100^{\circ}$ for $15 \mathrm{~min}$. to denature the blood and destroy the blood catalase. Cultures were streaked on plates of this medium and after incubation were tested as above.

Hydrolysis of arginine. Glucose $(0.5 \%, \mathrm{w} / \mathrm{v})$, arginine $(0.3 \%, \mathrm{w} / \mathrm{v})$ and agar $(0 \cdot 15 \%, w / v)$ were added to the basal medium. Inoculation was done as in the fermentation tests. One drop of each culture was tested for ammonia with Nessler's reagent after incubation for 3 days. Although $0.5 \%$ glucose inhibited the production of ammonia from arginine by some other strains, the activity of the strains described here was not affected.

Temperature requirements. The maximum temperatures for growth were determined by incubating cultures in tubes of basal medium to which were added glucose $(0.5 \%, \mathrm{w} / \mathrm{v})$ and one Pasteur pipette drop of a 24-hr culture. The tubes were plugged with sterile rubber stoppers and placed in water baths at $15^{\circ}, 37^{\circ}, 40^{\circ}, 43^{\circ}, 45^{\circ}$ and $50^{\circ}\left(\right.$ all $\left.\pm 1^{\circ}\right)$. Incubation was for 2 weeks at $15^{\circ}$ and 4 days at the other temperatures.

Hippurate hydrolysis. Cultures were grown in $5 \mathrm{ml}$. basal medium lacking citrate, but containing sodium hippurate $(1 \%, w / v)+$ glucose $(0.5 \%, w / v)$. After a few days the cultures were centrifuged and $50 \%(\mathrm{v} / \mathrm{v}) \mathrm{H}_{2} \mathrm{SO}_{4}$ was added to the supernatant fluid, which was allowed to stand overnight. The appearance of flat plate- 
like crystals of benzoic acid with a melting point of $121^{\circ}$ indicated a positive result. Needle-like crystals with a melting point of $187^{\circ}$ were assumed to be hippuric acid.

Aesculin hydrolysis. To the basal medium containing no citrate were added aesculin $(1 \%, \mathrm{w} / \mathrm{v})$, glucose $(0.25 \%, \mathrm{w} / \mathrm{v})$, ferric citrate $(0.05 \%, \mathrm{w} / \mathrm{v})$ and agar $(0 \cdot 15 \%, w / v)$. This medium was melted and cooled to $45^{\circ}$ before inoculation. Hydrolysis of aesculin was detected by the appearance of coral-like white crystals in the medium (Pl. 1, fig. 1), and a loss of fluorescence under the ultraviolet lamp. The crystals were isolated by melting the medium and pouring through filter paper. They dissolved in alkali to give a deep orangesolution which was not fluorescent. The crystals were assumed to be aesculetin, one of the hydrolysis products of aesculin. All cultures which produced crystals in the medium also showed loss of fluorescence, and no loss of fluorescence was noted in cultures where no crystals appeared.

Antibiotic sensitivity. Two drops of a 24-hr broth culture were spread on plates of basal agar medium containing glucose $(0.5 \%, w / v)$. Oxoid Multodises 11-15 F or 11-14D were placed on the plates, which were incubated in the inverted position for $24-48 \mathrm{hr}$ at $30^{\circ}$. Sensitivity was measured by the size of the zone of inhibition around the disc.

Motility. Initially motility was demonstrated by direct microscopical examination of young cultures in basal medium containing $0.5 \%(w / v)$ glucose. It was found, however, that all strains remained motile for a longer time when the medium contained only $\mathbf{0 . 0 5 \%}(\mathrm{w} / \mathrm{v})$ glucose. A macroscopic method for demonstrating motility in lactobacilli was devised. A spot inoculum was placed in the centre of a Petri dish containing 20-25 ml. of the soft agar medium used in the fermentation tests, with $\mathbf{0 . 5} \%(\mathrm{w} / \mathrm{v})$ glucose and bromocresol purple. The plates were not moved after inoculation. In non-motile strains the growth was restricted to the site of inoculation and the acid produced diffused slowly outwards. Motile strains produced diffuse growth throughout the agar and the whole plate soon became acid. There was $100 \%$ correlation between motility and the macroscopic appearance of the culture in the medium (Pl. 1, figs. 3, 4).

Flagella staining and electron microscopy. Strains 1 and 11 were grown on the basal medium $+0.05 \%(\mathrm{w} / \mathrm{v})$ glucose, which was used both as a liquid and as slopes containing $1.5 \%(\mathrm{w} / \mathrm{v})$ agar. Bacteria were harvested from the slopes by washing with sterile distilled water and from liquid medium by centrifugation. Harvested bacteria were then washed three times with sterile distilled water by centrifugation, and a final suspension prepared in distilled water.

Flagella staining was done by a modification of the method of Casares-Gil (Manual of Microbiological Methods, 1957). A drop of the bacterial suspension was streaked on the middle of a microscope slide and air-dried. As soon as drying was complete the preparation was treated for $5 \mathrm{~min}$. with a fixative $(60 \mathrm{ml}$. ethanol +30 ml. chloroform $+10 \mathrm{ml}$. neutral formalin) and washed in distilled water. The mordant $(10 \mathrm{ml}$.) was added to distilled water $(30 \mathrm{ml}$.) agitated slowly for $1 \mathrm{~min}$., and filtered on to the slide through a Whatman no. 12 filter paper. The mordant was allowed to act for 4-5 min. The slide was then washed, stained for $1 \mathrm{~min}$. with strong carbol fuchsin (Ziehl-Neelsen), washed again and air-dried. Photomicrographs were taken on a Zeiss Ultraphot microscope with Ilford R 20 plates.

For electron microscopy, droplets of the bacterial suspensions were placed on 
formvar-coated grids and shadowed with gold-palladium $(40 / 60, \mathrm{w} / \mathrm{w})$ at an angle of $15^{\circ}$. The grids were examined in a Siemens Elmiskop 1 with the single condenser system, a $200 \mu$ condenser aperture, a $50 \mu$ objective aperture and an accelerating voltage of $60 \mathrm{kV}$. Micrographs were taken at initial magnifications of $\times 8000$ and $\times 10,000$ on Ilford $\mathbf{N} 50$ plates.

\section{RESULTS}

The organisms studied are all Gram-positive rod-shaped bacteria with a tendency to form chains. None of them forms catalase on media free from haemin, reduces nitrate, grows well on ordinary media or forms spores. These properties place all the strains studied in the genus Lactobacillus. None of them produces gas from glucose. All grow at $15^{\circ}$ but not at $45^{\circ}$ except the $L$. salivarius strains, which grow at $45^{\circ}$ but not at $15^{\circ}$. All are motile in the early stages of growth. The soft agar medium of Whittenbury (1963) showed the carbon sources fermented and the way in which

\section{Table 1. Utilization of carbon sources by motile lactobacilli}

A, growth and acid production throughout; Aer, aerobic growth and acid production; An, anaerobic growth and acid production; Mic, micro-aerophilic growth and acid production; M, mutant growth and acid production; -, no acid production. Aer, A; An, A; Mic, A, first reaction followed later by second reaction.

Strain no.

$\begin{array}{ccccccccccc}1 \text { to } 7, & & 11 \text { to } 15, & 16 \text { to } & 21 \text { to } & 24, & & & & \begin{array}{r}\text { ATCC } \\ 929,\end{array} \\ 10 & 8,9 & 19,20 & 18 & 23 & 25 & 26 & 27 & 28 & \text { Ho } 66\end{array}$

Carbon

source

Glucose

Galactose

Mannose

Sorbose

Fructose

Rhamnose

Sucrose

Maltose

Cellobiose

Lactose

Melibiose

Trehalose

Melezitose

Raffinose

Arabinose

Xylose

Glycerol

Mannitol

Sorbitol

\begin{tabular}{|c|c|c|c|c|c|c|c|c|c|}
\hline $\mathbf{A}$ & $\mathbf{A}$ & $\mathbf{A}$ & $\mathbf{A}$ & $\mathbf{A}$ & $\mathbf{A}$ & $\mathbf{A}$ & $\mathbf{A}$ & $\mathbf{A}$ & $\mathbf{A}$ \\
\hline $\mathbf{A}$ & $\mathbf{A}$ & $\mathbf{A}$ & Aer, A & - & $\mathbf{A}$ & Aer, A & $\mathbf{A}$ & A & $\mathbf{A}$ \\
\hline A & $\mathbf{A}$ & $\mathbf{A}$ & $\mathbf{A}$ & $\mathbf{A}$ & An, $\mathbf{A}$ & Aer, A & $\mathbf{A}$ & Aer, A & $\mathbf{A}$ \\
\hline - & - & - & - & $\mathbf{A}$ & An, A & - & - & - & - \\
\hline $\mathbf{A}$ & A & $\mathbf{A}$ & $\mathbf{A}$ & $\mathbf{A}$ & An, A & Aer, A & $\mathbf{A}$ & Aer, $\mathbf{A}$ & $\mathbf{A}$ \\
\hline- & - & - & - & - & - & - & - & - & A or - \\
\hline Mic, $\mathbf{A}$ & Mic, A & An, A & An, $\mathbf{A}$ & $\mathbf{A}$ & An, A & - & - & A & $\mathbf{A}$ \\
\hline Mic, A & Mic, $\mathbf{A}$ & $\mathbf{A}$ & A & A & An, A & - & A & - & $\mathbf{A}$ \\
\hline A & $\mathbf{A}$ & $\mathbf{M}$ & An, $\mathbf{A}$ & $\mathbf{A}$ & $\mathbf{A}$ & - & $\mathbf{A}$ & - & - \\
\hline - & - & M & - & - & An & Aer & - & An & $\mathbf{A}$ \\
\hline- & - & - & - & - & - & - & - & $\mathbf{M}$ & $\mathbf{A}$ \\
\hline Mic, $\mathbf{A}$ & $\mathbf{A}$ & A or - & $\mathbf{A}$ & $\mathbf{A}$ & An, $A$ & Aer, A & - & $\mathbf{A}$ & $\mathbf{A}$ \\
\hline- & - & - & - & - & - & - & - & - & - \\
\hline- & - & - & - & - & - & - & - & - & $\mathbf{A}$ \\
\hline $\mathbf{A}$ & - & - & - & - & - & - & - & $\mathbf{A}$ & - \\
\hline- & - & - & - & - & - & - & - & - & - \\
\hline Aer & Aer & - & - & - & - & Aer & - & - & - \\
\hline An, $A$ & $\mathbf{A n}, \mathbf{A}$ & - & - & Aer & An & Aer & - & - & Aer \\
\hline- & - & - & - & Aer & An & - & - & - & Aer \\
\hline
\end{tabular}

acid was produced. The results are summarized in Table 1. Strains 1-10 produced less acid and grew more slowly on sucrose than on glucose media. These organisms are unique among the motile and non-motile homofermentative lactobacilli isolated during this work in that they did not decarboxylate malate (Table 2). They were sensitive to polymyxin $B$, to which all other strains studied here were resistant except strains 21, 22 and 23, which showed poorer growth near the polymyxin B disc.

Anaerobic initiation of acid production on disaccharides is common throughout the Lactobacillus plantarum-casei group, but the lactose- and cellobiose-fermenting 
mutants of strains 11 to 15,19 and 20 are unusual. When the lactose mutants are isolated and purified they ferment cellobiose constitutively, and the cellobiose mutants ferment lactose. These two disaccharides have a $\beta$-glycosidic linkage and are probably hydrolysed by the same $\beta$-glucosidase. Both lactose and cellobiose mutants produce growth throughout semi-solid agar with cellobiose as the energy source, but on lactose growth is restricted to the anaerobic portion of the medium, and neither mutant nor parent strains will utilize lactose in shallow broth cultures. This mutant behaviour with respect to lactose and cellobiose is restricted to these strains and a few non-motile organisms otherwise identical with them.

Table 2. Miscellaneous characters of motile lactobacilli

\begin{tabular}{|c|c|c|c|c|c|c|c|c|c|c|c|}
\hline \multirow[b]{2}{*}{ Character } & \multicolumn{11}{|c|}{ Strain no. } \\
\hline & $1-10$ & $\begin{array}{r}11-17 \\
19,20\end{array}$ & 18 & 21 & $22, \quad 23$ & 24 & 25 & 26 & 27 & 28 & $\begin{array}{c}\text { Hо } 66, \\
\text { АTCC } \\
929\end{array}$ \\
\hline Arginine & + & - & - & - & - & - & - & + & - & - & - \\
\hline Aesculin & - & - & - & + & + & + & + & - & - & - & - \\
\hline Hippurate & - & - & + & - & - & - & - & - & - & - & - \\
\hline Malate & - & + & + & - & - & + & + & + & + & + & + \\
\hline Malate + glucose & - & + & + & + & + & + & + & + & + & + & + \\
\hline Citrate & - & - & - & - & - & + & + & - & + & + & - \\
\hline Citrate + glucose & - & - & + & - & - & - & + & - & + & + & - \\
\hline $\begin{array}{l}\text { Catalase (heated- } \\
\text { blood medium) }\end{array}$ & + & - & - & + & - & - & - & + & + & + & - \\
\hline Dextran formation & - & - & - & - & + & + & + & - & - & - & - \\
\hline $37^{\circ}$ & + & + & + & + & + & + & + & + & + & + & + \\
\hline $40^{\circ}$ & + & + & + & - & - & - & - & + & + & - & + \\
\hline $43^{\circ}$ & - & - & - & - & - & - & - & + & - & - & + \\
\hline $45^{\circ}$ & - & - & - & - & - & - & - & - & - & - & + \\
\hline $50^{\circ}$ & - & - & - & - & - & - & - & - & - & - & - \\
\hline
\end{tabular}

Strain 28 is unique among these organisms in giving mutants able to ferment melibiose. In melibiose soft agar one or two fermenting colonies are produced in each tube. The mutant has been purified and has retained ability to ferment melibiose after subcultivation in a glucose medium, being otherwise identical with the parent culture. The parent culture was purified several times and continued to give melibiose-fermenting mutants. This is the only melibiose-fermenting organism of the low-temperature group which is motile.

Where glycerol was utilized, acid production was slight and only at the surface of the soft agar. This is to be expected since glycerol is a highly reduced substrate. It was surprising to find that mannitol, which is also more reduced than glucose, was fermented anaerobically by strains 1 to 10,24 and 25 , especially since strains 1 to 10 showed a tendency to grow microaerophilically on other substrates.

Dextran was formed by strains 22 to 25 (Pl. 1, fig. 2); this is an unusual property among the homofermentative lactobacilli. Since strains 22 and 23 differ from strains 24 and 25 in the way in which mannitol is utilized and in other properties, dextran production does not seem to be confined to any one particular type of streptobacterium. 
Flagella-stained preparations examined in the optical microscope (Pl. 2, figs. 5, 6) and electron micrographs (Pl. 2, figs. 7, 8, 9) showed lateral flagella in both strains. It appeared from ten examinations of each strain that all the bacteria possessed flagella. Pl. 2, fig. 8, clearly shows the insertion of flagella on an organism which has lost most of its contents through lysis.

\section{DISCUSSION}

With the exception of the two strains of Lactobacillus salivarius, the organisms examined here conform in all aspects except motility to the characters of the lowtemperature group of homofermentative lactobacilli, but they are not typical of either of the described species $L$. plantarum and $L$. casei. Since strain 28 mutates to melibiose fermentation the significance of ability to ferment this sugar in the classification of the streptobacteria may be questionable. None of the other motile strains ferment melibiose and therefore cannot be classified as L. plantarum (OrlaJensen, 1943; Wheater, 1955; Rogosa \& Sharpe, 1959). Many strains do not produce gas from citrate, many do not ferment mannitol, and one of them hydrolyses sodium hippurate. These properties exclude them from the species L. casei (Rogosa, Wiseman, Mitchell \& Disraely, 1953; Rogosa \& Sharpe, 1959).

That homofermentative motile lactobacilli may belong neither to Lactobacillus plantarum nor to $L$. casei is in agreement with the findings of previous authors (Cunningham \& Smith, 1940; Deibel \& Niven, 1958; Keddie, 1959). Harrison \& Hansen (1950) identified a motile organism from turkey faeces as $L$. plantarum and Mann \& Oxford (1954) found similar strains in the rumens of calves. Since all these organisms grew at $45^{\circ}$, and the latter strains did not grow at $16^{\circ}$, it seems possible that all were strains of $L$. salivarius. Hays \& Reister (1952) described motile lactobacilli from orange juice which they identified as $L$. plantarum var mobilis, but from the description given it is difficult to know whether these strains were in fact $L$. plantarum. Horowitz-Wlassowa \& Nowotelnow (1932) described a motile bacterium with a homolactic fermentation, but this organism formed spores and could therefore not be placed in the genus Lactobacillus (the authors proposed that it should be named $L$. sporogenes). The motile cytochrome- and catalase-containing organism described by Vankova (1957) would also appear to be more closely related to the aerobic spore-formers than to the lactobacilli. The properties of another Gram-positive motile bacterium are given in a paper by Kitahara \& Suzuki (1963). This organism differs from lactobacilli in forming spores, and in having less exacting nutrient requirements. The authors reported it as being catalase negative, an exceptional feature in the genus Bacillus. Thornley \& Sharpe (1959) described motile organisms with a homolactic fermentation of glucose, isolated from chicken meat. According to them, these organisms are intermediate between the lactobacilli and the aerobic spore-formers, although no spores were seen. It is difficult to assess the significance of these strains, since the meat from which they were isolated had been irradiated, and little is known of the effects of irradiation on bacteria. Langston \& Bouma (1960) isolated motile organisms from silage and called them $L$. casei (variable) since they resembled $L$. casei more closely than $L$. plantarum, while having some properties in common with the latter species.

Our strains 1 to 10 form a well-defined group and no similar non-motile organisms 
were isolated. The sensitivity to polymyxin $B$ and the inability to decarboxylate malate make these ten strains unique among the organisms studied; but in view of the small number of isolates and the fact that they all came from the same environment (grass silage) too much weight should not be attached to these differences. Strains 11 to 20 do not form such a clearly defined group; non-motile strains similar to these organisms have been isolated from the same samples of silage. Deibel \& Niven (1958), Keddie (1959) and Langston \& Bouma (1960) also found non-motile organisms otherwise similar to their motile strains. The strains of Keddie (1959) and some of those of Cunningham \& Smith (1940) did not ferment sucrose. Only two of our strains $(\mathbf{2 6}, \mathbf{2 7})$ did not ferment this substrate, but in the group of strains 1 to 10 acid production and growth on sucrose were slow as compared with growth on glucose.

Motility does not appear to be of taxonomic significance in this group since there is great variety in the other properties of these motile lactobacilli. In general these organisms ferment fewer carbon sources than do Lactobacillus casei or L. plantarum, but it is not possible to propose a new species to embrace these strains, since nonmotile organisms have been isolated which have the same properties as some motile strains. The finding that the two strains of $L$. salivarius examined are both motile shows that motility in the homofermentative lactobacilli is not restricted to the low-temperature group.

From the study of flagella-stained preparations, Cunningham \& Smith (1940) and Keddie (1959) thought motility was due to a single flagellum attached close to the pole of the cell. The organisms studied by Harrison \& Hansen (1950) had peritrichous flagella. That motile lactobacilli have numerous peritrichous flagella is also in agreement with the work of Langston \& Bouma (1960).

Two of the strains described have been deposited in the National Collection of Industrial Bacteria, Torry Research Station, Aberdeen. They are strain $\mathbf{1 1}=$ NCIB 9430 and strain $1=$ NсIB 9431. The electron microscopy described in this paper was carried out as part of the programme of the Department of Scientific and Industrial Research.

The authors thank Dr T. Gibson for helpful criticism given during preparation of the manuscript.

\section{REFERENCES}

Cunningham, A. \& Smith, A. M. (1940). The microbiology of silage made by the addition of mineral acids to crops rich in protein. II. The microflora. J. Dairy Res. 11, 243.

Deibel, R. H. \& Niven, C. F. (1958). Microbiology of meat curing. Appl. Microbiol. 6, 323.

Gibson, T., Stirling, A. C., Keddie, R. M. \& Rosenberger, R. F. (1958). Bacteriological changes in silage made at controlled temperatures. J. gen. Microbiol. 19, 112.

Harrison, A. P. \& Hansen, P. A. (1950). A motile lactobacillus from the cecal feces of turkeys. J. Bact. 59, 444.

HAYs, G. L. \& Reister, D. W. (1952). The control of 'off odor' spoilage in frozen concentrated orange juice. Food Tech. Champaign, 6, 386.

Horowitz-Wlassowa, L. M. \& Nowotelnow, N. W. (1932). Über eine sporogene Milchsäurebakterienart, Lactobacillus sporogenes nov. spec. Zbl. Bakt. (2. Abt.), 87, 331.

Keddie, R. M. (1951). The enumeration of lactobacilli on grass and in silage. Proc. Soc. appl. Bact. 14, 157. 
KeDdre, R. M. (1959). The properties and classification of lactobacilli isolated from grass and silage. J. appl. Bact. 22, 403.

KITAHARA, K. \& SUZUKI, J. (1963). Sporolactobacillus nov. subgen. J.gen. appl. Microbiol. 9, 59.

Langston, C. W. \& Bouma, C. (1960). A study of the microorganisms from grass silage. II. The lactobacilli. Appl. Microbiol. 8, 223.

ManN, S. O. \& Oxford, A. E. (1954). Studies of some presumptive lactobacilli isolated from the rumens of young calves. J. gen. Microbiol. $11,83$.

Manual of Microbiological Methods, Society of American Bacteriologists (1957). New York: McGraw-Hill.

Orla-Jensen, S. (1943). The Lactic Acid Bacteria. Ergänzungsband. Copenhagen: Ejnar Munksgaard.

Rogosa, M., Wiseman, R. F., Mrtchell, J. A. \& Disraely, M. N. (1953). Species differentiation of oral lactobacilli from man, including descriptions of Lactobacillus salivarius nov. spec. and Lactobacillus cellobiosus nov. spec. J. Bact. 65, 681.

Rogosa, M. \& Sharpe, M. E. (1959). An approach to the classification of the lactobacilli. J. appl. Bact. 22, 329.

Thornley, M. J. \& Sharpe, M. E. (1959). Micro-organisms from chicken meat related to both lactobacilli and aerobic spore-formers. J. appl. Bact. 22, 368.

VANKova, J. (1957). Motile catalase-producing strains of Lactobacillus delbrückii. Nature, Lond. 179, 204.

Wheater, D. M. (1955). The characteristics of Lactobacillus plantarum, L. helveticus and L. casei. J. gen. Microbiol. 12, 133.

Whittendury, R. (1963). The use of soft agar in the study of conditions affecting the utilization of fermentable substrates by lactic acid bacteria. J. gen. Microbiol. 32, 375 .

\section{EXPLANATION OF PLATES}

Plate 1

Fig. 1. Aesculin hydrolysis in $\frac{1}{2} \times 5$ in. test-tubes. Left, negative control. Right, positive result showing formation of coral-like crystals.

Fig. 2. Dextran production by strain 24 on sucrose agar.

Fig. 3. A non-motile lactobacillus growing in glucose soft agar.

Fig. 4. A motile lactobacillus growing in glucose soft agar.

Plate 2

Fig. 5. Photomicrograph, strain 1. Modified Casares-Gil stain, $\times 1000$.

Fig. 6. Photomicrograph, strain 11. Modified Casares-Gil stain, $\times 1000$.

Fig. 7. Electron micrograph, strain 1, gold-palladium shadow.

Fig. 8. Electron micrograph, strain 1, gold-palladium shadow.

Fig. 9. Electron micrograph, strain 11, gold-palladium shadow. 

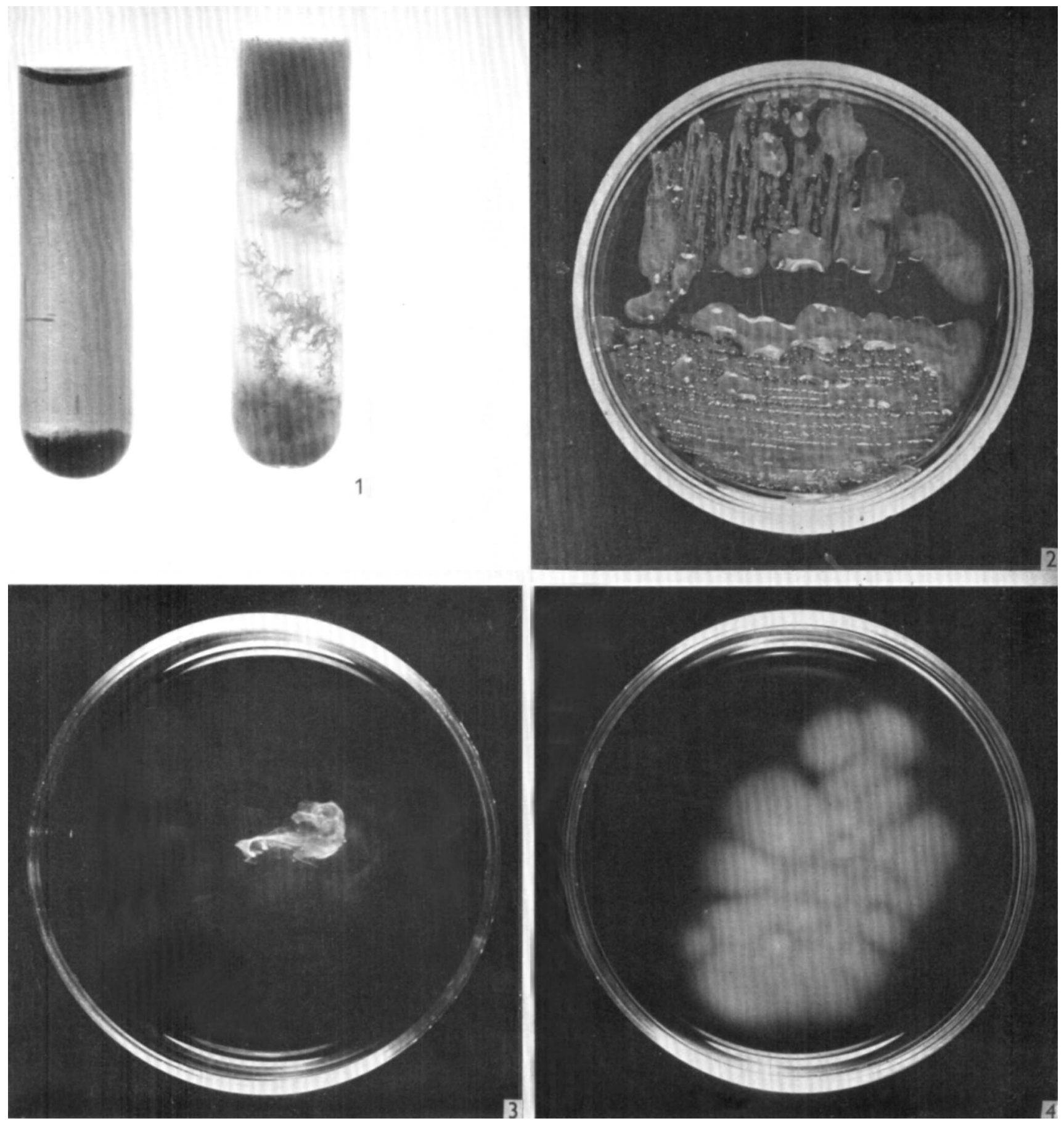

M. GEMMELL AND W. HODGKISS

(Facing p. 526) 
Journal of General Microbiology, Vol. 35, No. 3

Plate 2
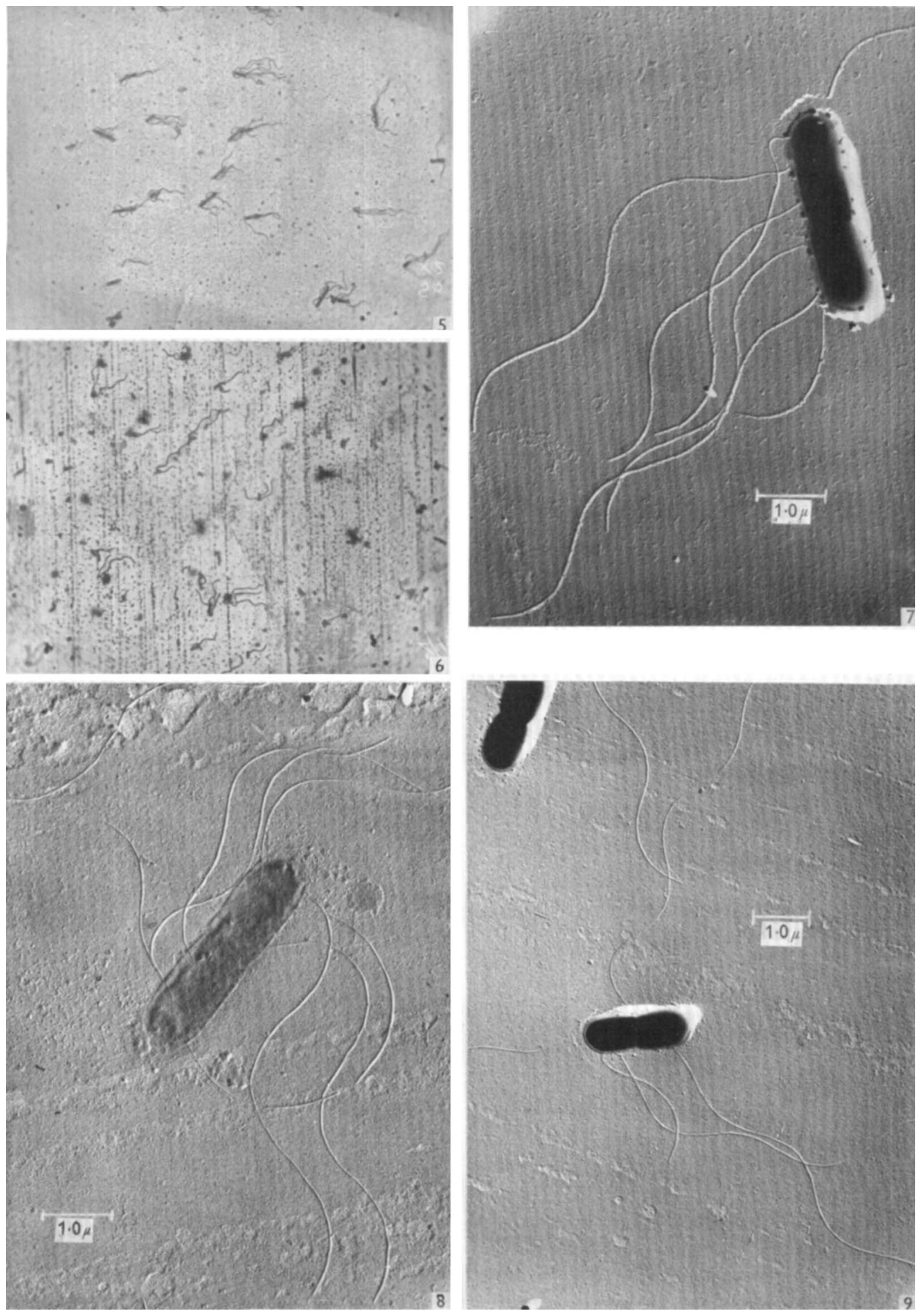

M. GEMMELL AND W. HODGKISS 